ANDRÉA REGINA GALVÃO PRESOTTO

\title{
INTERNACIONALIZAÇÃO DOS SISTEMAS DE SEGURIDADE SOCIAL - PERSPECTIVA DO BRASIL
}

\author{
DISSERTAÇÃO DE MESTRADO \\ ORIENTADOR: PROF. DR. SERGIO PINTO MARTINS
}

FACULDADE DE DIREITO DA USP

SÃO PAULO 


\section{INTERNACIONALIZAÇÃO DOS SISTEMAS DE SEGURIDADE SOCIAL - PERSPECTIVA DO BRASIL}

Dissertação de mestrado apresentada ao Departamento de Direito do Trabalho e da Seguridade Social como requisito parcial para obtenção do título de Mestre, sob orientação do Prof. Dr. Sergio Pinto Martins.

FACULDADE DE DIREITO DA USP

SÃO PAULO

2011 


\section{RESUMO}

PRESOTTO, Andréa Regina Galvão. Internacionalização dos sistemas de seguridade social - perspectiva do Brasil. Dissertação de Mestrado. Faculdade de Direito da Universidade de São Paulo, São Paulo, 2011.

Esta dissertação trata da internacionalização e necessidade de adequação dos sistemas de Seguridade Social ao atual cenário de circulação de mão-de-obra decorrente, principalmente, da globalização econômica e da formação dos blocos regionais. O primeiro capítulo é dedicado ao surgimento e evolução dos sistemas de Seguridade Social de acordo com o desenvolvimento dos Estados e aparecimento dos riscos sociais. A segunda parte dedica-se à análise de alsguns aspectos da globalização, bem como a relação estabelecida com a manutenção da soberania dos Estados, as perspectivas a partir da União Europeia e do Mercosul e, bem assim, os reflexos na Seguridade Social e os instrumentos utilizados para adequação dos sistemas, em busca da manutenção dos direitos sociais. Em seguida, são analisadas as diretrizes internacionais das Convenções n ${ }^{\circ}$ s 102 e 118 da OIT sobre Seguridade Social, bem como os sistemas internacionais atualmente vigentes nos principais blocos regionais, quais sejam, a União Europeia e o Mercosul. Finalmente, será estudado cada um dos acordos internacionais dos quais o Brasil é parte, com o objetivo de demonstrar a cobertura de proteção que um cidadão brasileiro ou natural de algum dos países envolvidos poderá usufruir. Em caráter complementar, será analisada a Convenção Ibero-americana de Seguridade Social que, apesar de já ratificada pelo Brasil, ainda não entrou em vigor, vez que não atingido o número mínimo de ratificações.

PALAVRAS-CHAVE: SEGURIDADE SOCIAL, LIVRE CIRCULAÇÃO DE MÃO-DEOBRA, GLOBALIZAÇÃO, BLOCOS ECONÔMICOS, ADEQUAÇÃO DOS SISTEMAS. 


\section{ABSTRACT}

PRESOTTO, Andréa Regina Galvão. Internacionalização dos sistemas de seguridade social - perspectiva do Brasil. Dissertação de Mestrado. Faculdade de Direito da Universidade de São Paulo, São Paulo, 2011.

The present dissertation addresses the internationalization and the need to adequate Social Security systems to the current scenario of movement of labor, mainly due to the economic globalization and the formation of regional trade blocs. The first chapter is dedicated to the analysis of the emergence and evolution of Social Security systems according to the development of the National States and the emergence of social risks. The second part of the paper analyzes issues related to the globalization, the relationship established with the maintenance of sovereignty of the States, the perspectives from the European Union and from the Mercosur, as well as its reflections in the Social Security and the instruments used to adequate the systems, in pursue to maintaining social rights. Subsequently, the international guidelines of ILO Conventions No 102 and 118 about Social Security, as well as the international systems currently in force in the main regional blocs, namely European Union and Mercosur, will be assessed. Finally, each of the agreements signed by Brazil will be studied, aiming to demonstrate the protection coverage, of which a Brazilian citizen or a citizen of one of the countries in plot can make use. Additionally, we will analyze the Iberoamerican Convention of Social Security that, despite already ratified by Brazil, is still not in force as the minimum number of ratifications has not been achieved yet. 
KEYWORDS: SOCIAL SECURITY, FREE MOVEMENT OF LABOR, GLOBALIZATION, ECONOMIC BLOCS, ADEQUACY OF SYSTEMS. 


\section{INTRODUÇÃO}

\section{Justificativa da escolha e da importância do tema}

O fenômeno da globalização trouxe (e ainda traz) inovações no relacionamento entre os Estados. Aqueles geograficamente distantes, porém próximos em suas ambições, interagem com o fim de dinamizar as relações e romper barreiras. Já os Estados que gozam de interesses comuns e de proximidade territorial fizeram com que o mundo se dividisse em blocos econômicos.

Os blocos econômicos refletem as características de seus respectivos Estados-membros. Por tal razão, na exata medida em que os países que os compõem harmonizam seus interesses e ultrapassam os obstáculos nacionais, amplia-se a integração. Tais blocos podem ser classificados por estágios de desenvolvimento. Nas palavras de Ari Possidonio Beltran ${ }^{1}$, “a partir do terceiro estágio, ou seja, do mercado comum, entre a plena vigência das liberdades fundamentais, está a livre circulação de trabalhadores dos Estados-membros”.

Dentro ou fora de blocos econômicos, as empresas nacionais, que antes tinham a maior parte de seus concorrentes limitada ao âmbito territorial interno, passaram, com a integração de seus respectivos países, a concorrer diretamente com as companhias estrangeiras. O mercado globalizado introduz no mercado interno produtos e serviços estrangeiros, com custos, em certos casos, reduzidos, que acirram a competição comercial.

Mas não é só. A estrutura das empresas multinacionais sucumbiu ante a das chamadas empresas globais. Se no passado cada uma das sucursais se organizava como uma réplica parcialmente autônoma em relação à matriz, hoje a própria produção é globalizada. No modelo das empresas globais, as respectivas unidades, localizadas em

\footnotetext{
${ }^{1}$ BELTRAN, Ari Possidonio. O sistema de Seguridade Social ante a globalização da economia. São Paulo. Revista do Advogado n ${ }^{\circ}$ 80. p. 7.
} 
países diversos, podem e precisam compartilhar produtos semi-acabados, tecnologia e mão-de-obra, em um ambiente de dependência recíproca² ${ }^{2}$.

Decorre do estreitamento de relações entre os Estados o fato de romperem-se - ou, ao menos, reduzirem-se - os entraves para a circulação de pessoas, inclusive trabalhadores.

Inarredável, portanto, que a globalização e a formação dos blocos econômicos tendam a propiciar o intercâmbio de mão-de-obra.

Note-se, aliás, que o que ainda se afigura como tendência para alguns blocos já é fato em outros. Tal é o caso da União Europeia, cujo estágio de integração já atingiu patamares máximos com a união monetária (criação e implantação do euro, como moeda comum), em que também se verifica a concretização da livre circulação de trabalhadores.

Dada a intenção de a grande maioria dos países integrarem-se, ainda que tal intenção não passe, em certos casos, de verdadeira tentativa de manutenção da autonomia econômica e sustentação das relações financeiras, a circulação dos trabalhadores tornou-se um fenômeno comum.

Nesse passo, forçosa é a preocupação com temas e garantias dos direitos sociais destes trabalhadores que, em razão de suas atividades profissionais, migram para um país estrangeiro e lá permanecem por certo período de tempo.

O fato é que a efetiva integração entre os Estados apenas será alcançada quando a garantia dos direitos sociais se der de forma plena. Para que os trabalhadores

\footnotetext{
${ }^{2}$ Nesse sentido, lição de WALKÜRE LOPES RIBEIRO DA SILVA:

"As novas condições de concorrência ditadas por esses fatores geraram uma divisão internacional do trabalho com desdobramentos inesperados e originais: em um primeiro momento, as empresas transnacionais passaram a fabricar os componentes dos produtos em diferentes países, em busca de mão-de-obra e insumos baratos, de modo que se pode dizer que os produtos são multinacionais (o "carro mundial" é um exemplo); em um segundo momento, as próprias empresas não são mais organizadas em unidades nacionais.

Como relata Peter F. Drucker, as empresas passaram a ser administradas "como um sistema mundial no qual cada uma das tarefas distintas - pesquisa, projeto, engenharia, desenvolvimento, testes e, cada vez mais, manufatura e 'marketing' - é organizada de forma transnacional.

Em resumo, hoje ocorrem tanto a globalização do mercado como a globalização da própria produção, o que constitui algo completamente novo em relação ao passado e tem conseqüências dramáticas na esfera estatal.” (SILVA, Walküre Lopes Ribeiro da. Crise de representatividade e participação dos sindicatos em políticas ativas de emprego. 2001. p. 37-38. Tese (Titular de Direito do Trabalho) - Faculdade de Direito da Universidade de São Paulo, São Paulo, 2001).
} 
possam circular, para que as empresas (internacionais ou não) possam investir em sua mãode-obra, garantindo competitividade, é imprescindível que se assegure à força humana harmonia no sistema de seguridade social, a fim de que se evitem impactos desastrosos.

Marcus Orione Gonçalves Correia e Érica Paula Barcha Correia ${ }^{3}$, ao tratarem da seguridade social a partir de uma perspectiva política, ensinam que a seguridade social "estende-se a toda a sociedade e tem como principal prestador o Estado, em missão fundamental.”

É exatamente nesse aspecto que se encontra o principal desafio dos Estados em relação à seguridade social e ao fenômeno da globalização: não há dúvidas quanto à imprescindibilidade da garantia do sistema de seguridade social efetivo aos trabalhadores que circulam entre os países, todavia os caminhos para que se alcance tal propósito ainda são tortuosos, especialmente por conta das diferenças dos sistemas nacionais ${ }^{4}$. Veja-se, nesse sentido, a lição de Mc Gillivay ${ }^{5}$ :

Em todo programa de seguridade social se deve levar em consideração as circunstâncias nacionais. É necessário recordar sempre que, o que funciona bem em um país, em outro pode ser profundamente inadequado.

Para Américo Plá Rodriguez ${ }^{6}$ a circulação de trabalhadores é um dos fatores que implica a necessidade de reavaliação dos sistemas de seguridade social:

O quinto fator é a circulação dos trabalhadores de um país para outro, nos processos de integração regional.

\footnotetext{
${ }^{3}$ CORREIA, Marcus Orione Gonçalves; CORREIA, Érica Paula Barcha. Curso de Direito da Seguridade Social. São Paulo: Saraiva, 2007. p.15.

${ }^{4}$ Neste sentido, ensina Bernd Von Maydell: "Os sistemas de seguridade social têm suas raízes em considerações nacionais do Estado. Até hoje, os países defendem com unhas e dentes o seu monopólio quanto ao direito de decisão no setor da política social. Essa questão é verdadeira para a União Européia. Onde uma política social comum está aos poucos sendo elaborada. Tal alinhamento nacional de sistema da seguridade social confronta-se com a globalização de mercados e a crescente mobilidade dos indivíduos. Se as fronteiras erigidas pela existência contínua de sistemas de seguridade social nacionais não devem prejudicar a globalização e as tendências de mobilidade, será necessário dedicar, no futuro, maior atenção às leis internacionais”(MAYDELL, Bernd von. Perspectivas da seguridade social. In: Seminário Internacional Relações de Trabalho, Anais... Brasília: MTb, 1998. p. 324-325.

${ }^{5}$ Apud PLÁ RODRIGUEZ, Américo. A perspectiva da seguridade social. In: Seminário Internacional Relações de Trabalho, Anais... Brasília: MTb, 1998. p. 338.

${ }^{6}$ Ibid. p. 334.
} 
Essa circunstância acentua um problema que já se havia apresentado pela comunicação entre países limítrofes, mas que agora deve se encarar definitivamente, porque tudo faz crer que o fenômeno se intensificará pelo estreitamento dos laços entre os países associados.

A integração regional demanda a existência de meios que garantam a proteção social dos trabalhadores. A concretização de tais meios, por sua vez, depende da criação de modelo jurídico que permita ao trabalhador o efetivo acesso ao sistema de seguridade social tanto no país de origem como no país em que irá desenvolver sua atividade profissional.

\section{Principais questões a serem analisadas}

Nessa esteira, como tentativa de tratar das questões envolvidas no tema e suas repercussões, a dissertação será estruturada de forma que uma análise interdisciplinar seja alcançada.

O Capítulo I cuidará do desenvolvimento das normas de proteção social. É analisada a evolução das normas de proteção social desde as primeiras manifestações de proteção social na Antiguidade até o modelo que hoje vige no Brasil, inclusive com a análise das experiências inglesa e alemã, a partir das respectivas iniciativas de Beveridge e Bismarck.

O aprimoramento simultâneo entre o desenvolvimento das normas e técnicas de cobertura de contingências e os modelos político-econômicos de cada época, demonstra o progresso dos sistemas de seguridade social de acordo com as mudanças político-sociais.

Esta análise indicará a importância do tema, uma vez que a atual situação político-econômica e o fenômeno da globalização clamam pela adequação dos sistemas de 
seguridade social, da mesma forma que o Estado Liberal redundou, no século XIX, na criação de um sistema peculiar de proteção social ${ }^{7}$.

O Capítulo II tratará do fenômeno da globalização. Serão analisados os aspectos e estágios deste fenômeno e os impactos nos Estados, especialmente em relação à livre circulação de trabalhadores e a consequente necessidade de adequação dos sistemas de seguridade social.

Dentre os aspectos da globalização, a dificuldade em se estabelecer o alcance ou restrição da soberania dos Estados tem grande relevância. Ao integrar uma comunidade internacional, um bloco econômico, até que ponto um Estado-membro está fazendo jus ou abrindo mão de sua soberania?

Para responder a questão, necessário recorrer às lições de Direito Internacional, aos conceitos de Estado, soberania e território e suas evoluções para apontar os impactos da integração também sob o ponto de vista da conjugação do direito interno com o internacional.

Sob esta perspectiva, importante o estudo dos instrumentos de adequação internacional dos sistemas de seguridade social. As soluções possíveis a serem aplicadas para efetivar a internacionalização e possibilitar a real integração dos Estados com a concretização da livre circulação de trabalhadores.

O Capítulo III cuidará dos sistemas comunitários de seguridade social hoje vigentes, a partir dos blocos econômicos existentes.

Para possibilitar a análise sob o ponto de vista da contingência e respectiva cobertura internacional, serão apontados os riscos considerados passíveis de cobertura inter-Estados e sua relação com o desenvolvimento de um trabalho remunerado.

\footnotetext{
${ }^{7}$ Ensina Marco Aurélio Serau Junior: "Uma incipiente forma de 'proteção social' pode ser identificada, nesse período e modelo histórico, no chamado paternalismo industrial, adotado especialmente entre a metade do século XIX e as primeiras décadas do século XX.

Consistia o paternalismo industrial num conjunto de práticas sociais desenvolvidas pelos empregadores, em relação a seus empregados, caracterizadas pela assunção de responsabilidades atinentes à melhora da qualidade de vida do trabalhador, resultando esta em certa melhoria das condições contratuais relativas a salários e condições de trabalho.” SERAU JUNIOR, Marco Aurélio. Seguridade Social como Direito Fundamental Material. Curitiba: Juruá, 2009. p.132.
} 
Apontados principais riscos sociais internacionalmente considerados, serão analisados os sistemas de seguridade social da União Européia e Mercosul.

Finalmente, o Capítulo IV trará estudo voltado especificamente para as relações internacionalmente estabelecidas pelo Brasil

Destarte, serão apontados os aspectos do relacionamento internacional mantido pelo Brasil no que se refere à proteção social. Logo, além da posição no Mercosul, os dez tratados internacionais dos quais o país é atualmente signatário serão refletidos no trabalho.

Será demonstrada a situação do Brasil no que se refere à internacionalização dos direitos sociais e, por conseguinte, a rede de proteção social atualmente disponível aos cidadãos brasileiros.

Assim, será objeto do presente estudo tema atual, de grande impacto e importância no desenvolvimento da Seguridade Social, a qual, a despeito de estar cerceada pelas peculiaridades dos sistemas de cada Estado, insere-se no contexto da proteção internacional aos direitos humanos.

\section{Metodologia a ser utilizada}

O estudo comportará a análise dos aspectos históricos e pesquisa bibliográfica.

Serão estudados autores nacionais e estrangeiros, bem como analisados os textos normativos específicos.

Vale enfatizar que se trata de análise interdisciplinar da matéria, envolvendo o direito internacional, direito constitucional, direito do trabalho e direito da seguridade social. 


\section{CONCLUSÃO}

Os sistemas de Seguridade Social nem sempre foram normatizados de forma orgânica, capaz de oferecer a todos os cidadãos a rede de proteção necessária para a cobertura de todas as contingências sociais.

As primeiras medidas para remediar as situações de necessidade sequer partiam do Estado, vinham principalmente de grupos da sociedade com afinidades, especialmente profissionais, e da Igreja.

As associações de profissionais de mesma categoria organizaram-se também com o objetivo de proporcionar auxílio em casos de doenças e velhice. A primeira celebração de seguro consta de 1344, com o seguro marítimo.

Com a evolução das formas de organização da sociedade, as normas de Seguridade Social passam também a adequar-se às contigências. Principalmente após a Revolução Industrial, as condições de trabalho e os riscos delas decorrentes passam a ser o principal objetivo da rede de proteção social.

No Estado Liberal, a ausência de qualquer ingerência estatal na vida em sociedade redundou em completo desamparo da população, que já não contava mais com as redes de proteção que lhe garantia o mínimo de cobertura pelo menos em relação aos riscos naturais. Surge o paternalismo industrial.

Diante da degradação dos direitos sociais o Estado retoma a responsabilidade pela proteção. Verificam-se as propostas de adoção de seguros sociais na Alemanha, pelo Chanceler Otto von Bismarck. As Constituições do México, em 1917 e de Weimar, em 1919, marcam o início da constitucionalização dos direitos sociais.

Inversamente ao Estado Liberal, no Welfare State a intervenção estatal produziu uma série de normas e medidas que visavam garantir o bem-estar dos cidadãos.

A Seguridade Social passa a ter abrangência mais universal, deixando de atuar restritamente nos infortúnios ligados à vida profissional e revelando preocupações, 
por exemplo, com a idade avançada. O Plano Beveridge, de 1942, proteção do berço ao túmulo, é o marco da universalização da Seguridade Social.

O Welfare State passa a ser alvo de críticas e é sucedido pelo Estado Neoliberal. A liberalização do mercado e o afrouxamento das regulações estatais sobre a indústria privada também contribuíram para a concretização do fenômeno da globalização e, sem dúvida, impactaram nos sistemas de Seguridade Social.

No Brasil, o registro da primeira norma de Seguridade Social data de 1543, com caráter substancialmente assistencialista e o cenário brasileiro foi marcado pela sucessão de leis esparsas e constituições que já previam o sistema previdenciário e o tríplice custeio.

Atualmente, a evolução das normas de Seguridade Social culminou na redação do art. 194 da Constituição Federal e das Leis 8.212 e 8.213, ambas de 1991, que regulamentam o sistema brasileiro.

Embora comumente se relacione a globalização a um fenômeno tipicamente econômico, seus reflexos alcançam diretamente outros aspectos, dentre eles, a Seguridade Social.

Com a intensificação da globalização nas últimas décadas, a reflexão acadêmica também passou a dedicar-se ao processo que permeia questões econômicas e financeiras, além de resvalar na dúvida propriamente quanto à manutenção da soberania dos Estados.

A noção de território como limite do poder soberano já não tem mais lugar em um cenário globalizado. A queda das barreiras territoriais e as questões relacionadas à soberania fazem surgir um desafio também para o Direito, especialmente para o ramo do Direito Constitucional, a partir da percepção de que a Constituição, antes suprema para dirimir os conflitos internos, apresenta lacunas e, muitas das vezes, conflitos, no plano internacional.

Surge, assim, como resultado da integração dos Estados, a tendência à criação de normas constitucionais supraestatais, com clara concessão de parcelas do poder soberano em prol da união comunitária. 
Aquilo que antes era exclusivamente regulado pelo ordenamento interno passa a sofrer alterações, formando um emaranhado de ordenamentos jurídicos resultado da integração dos Estados.

A noção de soberania passa a ter outra perspectiva, assumindo muito mais um caráter de regulação das competências que poderão ser concedidas para a formação do arcabouço jurídico transnacional.

O impacto das concessões é, no entanto, a degradação dos direitos sociais, a adapatação do Estado ao meio comunitário em que está ou pretende se integrar influencia na manutenção das garantias sociais, razão pela qual o Estado deve passar a ter também a preocupação de assegurar os direitos já conquistados de seus cidadãos diante das estruturas de poder que se formam além das barreiras territoriais.

No Brasil, o artigo $4^{\circ}$ da Constituição demonstra a intenção do legislador constituinte em estabelecer a integração com os demais Estados sem, contudo, macular a indenpendência da nação.

A posição adotada pelo Mercosul, de acordo com o Protocolo de Ouro Preto, indica que os países não pretendem ceder qualquer parcela de sua soberania, ao contrário do que ocorre na União Europeia em que os Estados cedem parcelas de seu poder soberano à ordem comunitária.

No que se refere à Seguridade Social, o que se propõe é uma globalização social, de modo a garantir a efetiva circulação dos trabalhadores, além do mero trânsito, mas assegurando a rede de proteção social tal qual aquela oferecida aos nacionais do país de trabalho.

Com esse objetivo, não se pode admitir a criação de um sistema de Seguridade Social especial para os estrangeiros, mas sim a extensão a todos os residentes em um determinado território, das mesmas condições sociais.

Os instrumentos de adequação dos sistemas, portanto, são a criação de um sistema único, a harmonização das normas ou a coordenação. 
Os sistemas comunitários de Seguridade Social eleitos para estudo foram os vigentes na União Europeia e Mercosul.

Ambos devem seguir as normas mínimas de Seguridade Social estabelecidas pela Convenção $\mathrm{n}^{\circ} 102$ da OIT. Dentre os principais aspectos, verifica-se a necessidade de aplicação de pelo menos três seções de prestações e benefícios previdenciários, além da obrigatoriedade de observância nos critérios de cálculo de pagamento e igualdade de tratamento para residentes estrangeiros.

Os serviços médicos devem ser prestados em caráter universal , sem distinção da doença e suas causas.

As prestações de auxílio doença, desemprego, acidente de trabalho e doenças profissionais relacionam-se à suspensão de ganhos e a idade para a concessão de aposentadoria por velhice é de 65 anos.

Finalmente, os acordos bilateriais e multilaterais dos quais o Brasil é parte tratam de diversos aspectos de cobertura, na sua maioria relacionados à invalidez, velhice, acidente de trabalho e doenças profissionais, sempre perpetrando a igualdade entre o nacional e o estrangeiro como forma de possibilitar e até mesmo incentivar a circulação de pessoas.

A garantia ao trabalhador e seus familiares que, em caso de contingências, não permanecerá em desemparo, é essencial para viabilizar a circulação e o intercâmbio da mão-de-obra, revelando, mais uma vez, a importância e a necessidade de adequação dos sistemas de Seguridade Social ao cenário atual. 


\section{REFERÊNCIAS BIBLIOGRÁFICAS. OBRAS CITADAS OU CONSULTADAS.}

ACCIOLY, Elizabeth. Mercosul e União Européia: Estrutura Jurídico-Institucional. Curitiba: Juruá, 1996.

ADOLFO, Luiz Gonzaga Silva. Globalização e Estado Contemporâneo. São Paulo: Memória Jurídica Editora, 2005.

ALEMANY, Macário. El paternalismo jurídico. Madrid: Iustel, 2006.

AQUINO, Sônia Aparecida M. Tomaz de. A livre circulação de trabalhadores no Mercosul. In: Mercosul das negociações à implantação, São Paulo: LTr, 1995.

ARENAS DE MESA, Antonio. Aprendendo com as reformas previdenciárias: os exemplos do Chile $\quad$ do da Argentina. Disponível: http://www.mpas.gov.br/07_03_01_04.htm

AZEVEDO, Plauto Faraco de. Direito, justiça social e neoliberalismo. São Paulo: Revista dos Tribunais, 1999.

BALERA, Wagner. Sistema de seguridade social. 4. ed. São Paulo: LTr, 2006. . (coordenador). Curso de direito previdenciário. 4. ed., São Paulo: LTr, 1998. O tratado internacional e o sistema previdenciário nacional. Revista de Previdência Social (RPS). São Paulo, nº 178.

BAPTISTA, Luiz Olavo. O Mercosul, suas instituições $e$ o ordenamento jurídico. São Paulo: LTr, 1998.

BARROS JÚNIOR, Cássio de Mesquita. Perspectivas do direito do trabalho no Mercosul. Tese (Titular) - Faculdade de Direito, Universidade de São Paulo, 1993. 
BASSO, Maristela (organizadora). MERCOSUL - seus efeitos jurídicos, econômicos $e$ políticos nos estados-membros. 2. ed. São Paulo: Livraria do Advogado, 1997.

Os limites entre o direito internacional e o direito da integração. Série Estudos Jurídicos, volume 27, nº 71, set./dez. 1994.

BELTRAN, Ari Possidonio. Os impactos da integração econômica no direito do trabalho: globalização e direitos sociais. São Paulo: LTr, 1998.

. O sistema de Seguridade Social ante a globalização da economia. São Paulo. Revista do Advogado nº 80, 2004.

BERCOVICI, Gilberto; MASSONETTO, Luís Fernando. Breve história da incorporação dos direitos sociais nas Constituições democráticas brasileiras. Revista do Departamento de Direito do Trabalho e da Seguridade Social. Departamento de Direito do Trabalho e da Seguridade Social da Faculdade de Direito da USP. São Paulo, v. 2, n. 3, jan./jun., 2007.

BERTOLIN, Patrícia Tuma Martin. A harmonização dos sistemas de seguridade social no mercosul . Revista de Previdência Social. São Paulo: LTr, v 21, nº 202 p. 867-870. 1997.

BEVERIDGE, Sir William. O plano Beveridge: relatório sobre o seguro social e serviços afins. Tradução de Almir de Andrade. Rio de Janeiro: José Olympio, 1943.

BODIN, Jean. Los seis libros de la república. Trad. de Pedro Bravo Gala. 3. ed. Madrid: Tecnos, 1997

BOSSU, Bernard. Harmonisation européene et contrat de travail. In JAMIN, Christofe; MAZEAU, Denis (Dir.). L'harmonisation du droit des contrats en Europe. Paris: Economica, 2001.

CABO, José Maria. La economia como ideología: mitos, fantasias y creencias de la ‘ciencia’ económica. Hondarribia: Editorial Hiru, 2004.

CARVALHO FILHO, Celecino de. Tendências dos sistemas de previdência social na América do sul . Revista de Previdência Social. São Paulo: LTr, v 24, nº 233, p. 371-374, abril de 2000 . 
CARVALHO, José Murilo de. Cidadania no Brasil: o longo caminho. 9. ed. Rio de Janeiro: Civilização Brasileira, 2007.

CASELLA, Paulo Borba (Coord.). MERCOSUL: integração regional e globalização. Rio de Janeiro: Renovar, 2000.

Fundamentos do direito internacional pós-moderno. São Paulo: Quartier Latin, 2008.

CASTEX, Paulo Henrique. Os blocos econômicos como sociedade transnacional - A Questão da Soberania. In CASELLA, Paulo Borba (Coord.). MERCOSUL: integração regional e globalização. Rio de Janeiro: Renovar, 2000.

CASTRO, Alberto Pereira de; et al. Manual de direito previdenciário. 3. ed., São Paulo: LTr, 2002.

CHIARELLI, Matteo Rota. A livre circulação de trabalhadores no Mercosul. In:Temas de integração com enfoque no MERCOSUl, vol. 01, São Paulo: Ltr, 1997.

COMPARATO, Fábio Konder. A afirmação histórica dos direitos humanos. 4. ed. Ver. E atual. São Paulo: Saraiva, 2005.

CORREIA, Marcus Orione Gonçalves. Um mundo em mudança e a seguridade social. Revista de Previdência Social. São Paulo: LTr, v 21, nº 203, p. 984-988, outubro de 1997.

. Uma análise comparativa entre o sistema de seguridade social brasileiro e o japonês - em busca de soluções para os trabalhadores brasileiros residentes no Japão. Revista de Previdência Social (RPS) nº 258. São Paulo, 2002.

e CORREIA, Érica Paula Barcha. Curso de direito da seguridade social. 3. ed.,São Paulo: Saraiva, 2007.

COSTA, Eliane Romeiro. Tendências do sistema de previdência social. São Paulo: Revista de Previdência Social, v 25, nº 252, p. 790-797, novembro de 2001.

COSTA, José Ricardo Caetano. Seguridade social dos países do mercosul . Revista de Previdência Social. São Paulo: LTr, v 24, n 233, p. 341-350, abril de 2000. 
DALLARI, Pedro Bohomoletz de Abreu. O mercosul perante o sistema constitucional brasileiro. In: Temas de integração com enfoque no MERCOSUL, vol. 01, São Paulo: LTr, 1997.

DELGADO, Ignácio Godinho. Previdência social e mercado no Brasil. São Paulo: LTr, 2001.

DEJOURS, Christophe. Conferências brasileiras: identidade, reconhecimento $e$ transgressão no trabalho. Tradução de Ana Carla Fonseca Reis. São Paulo: EAESP/FGV, 1999.

A banalização da injustiça social. 7. ed. Tradução de Luiz Alberto Monjardim. Rio de Janeiro: FGV, 2007.

DI PIETRO, Adriano. Le sanzioni tributarie nell'esperienza europea . Milano: Dott. A. Giuffrè editore, 2001.

DREYSYM DE KLOR, Adriana. El Mercosur generador de una nuieva fuente de derecho internacional privado. Buenos Aires, 1997.

DRUCKER, Peter. The next society; a survey of the near future. In The Economist, p. 313, November $3^{\text {rd }} 2001$.

DUGUIT, Léon. Soberania y libertad - lecciones dadas en la Universidade de Columbia (New York).Trad. y prólogo por José G. Acuña. Madrid: Francisco Beltrán Librería Española y Extranjera, 1924.

FARIA. José Eduardo. Direitos Humanos e globalização econômica: notas para uma discussão. Estudos Avançados. Nº 30. S.Paulo: IEA-USP, maio-agosto de 1997.

FARIAS, Paulo José Leite. A seguridade social na união européia como expressão de proteção internacional de direitos fundamentais. Revista da Procuradoria Geral do INSS. Brasília, vol. 04, nº 01, abril/junho de 1997.

FERNANDES, Anníbal. Poder econômico versus previdência social. São Paulo: Tribuna da Justiça, 1995. 
. Previdência e o direito a obter direitos. São Paulo: In: Revista Brasileira de Direito. Notas Informativas., v.1, n.1, p. 48, set. 1997.

. Direitos adquiridos e direitos em formação . São Paulo: In Jornal do $10^{\circ}$ Congresso Brasileiro de Previdência Social. LTr, p. 16, 28 e 29 de julho de 1997.

FERRAJOLI, Luigi. Derechos y garantías - la ley del más debil . Madrid: Editorial Trotta, 1999.

FERREIRA, Aldo Leão. MERCOSUL: Comentários sobre o tratado de Assunção e o Protocolo de Brasilia. Porto Alegre: Livraria do Advogado, 1994.

FERREIRA, Dâmares. O Princípio da dignidade da pessoa humana e os benefícios previdenciários . Revista de Previdência Social. São Paulo: LTr, nº 255, p. 124-135, fevereiro de 2002.

. Previdência social, instrumentalização da dignidade da pessoa humana. Revista de Previdência Social. São Paulo: LTr, nº 252, p.802-813, novembro 2001.

FERREIRA FILHO, Manoel Gonçalves. Aspectos do Direito Constitucional contemporâneo. S. Paulo: Saraiva, 2003.

FERREIRA, María Carmem; OLIVEIRA, Julio Ramos. MERCOSUR: enfoque Laboral. Montevideo: FCU, 1994.

FRANCO FILHO, Georgenor de Sousa. Globalização do trabalho: rua sem saída. São Paulo: LTr, 2001.

FREITAS JUNIOR, Antônio Rodrigues de. Os direitos sociais como direitos humanos num cenário de globalização econômica e de integração regional In: PIOVESAN, Flávia (Coord.). Direitos humanos, globalização econômica e integração regional: desafios do direito constitucional internacional. São Paulo: Max Limonad, 2002.

FRIEDMAN, M. Speaking the truth about social security reform. Briefing papers, $\mathrm{n}^{\circ} 46$, Cato Institute. Washington, D.C., 1999. 
FUENTE, Eustasio Del Val y de la. Lecciones de seguridad social. Barcelona: Centro de Estudios Financieros, v.2, 1991.

FUKUYAMA, Francis. La construcción del Estado: hacia un nuevo orden mundial en el siglo XXI. Tradução de María Alonso. Barcelona: Ediciones B, 2004.

GARCÍA OVIEDO, Carlos. Tratado Elemental de Derecho Social. Madrid: ESPESA, 1948.

GIGLIO, Wagner D. OIT e Convenções Internacionais do Trabalho ratificadas pelo Brasil. São Paulo: Sugestões Literárias, 1973.

GRIMM, Dieter. Constitucionalismo y derechos fundamentales. Tradução de Raúl Sanz Burgos y José Luis Muñoz de Baena Simón. Madrid: Trotta, 2006.

HORVATH JUNIOR, Miguel. A previdência social em face da globalização. São Paulo: Quartier Latin, 2006.

HUSEK, Carlos Roberto. Curso de Direito Internacional Público. 2a ed. São Paulo: LTr. 1998.

JAMES, Estelle. New models for old-age security: experiments, evidence, and unanswered questions. In: The World Bank Observer. Washington, D.C.: n.2, p. 271-301, vol. 13, 1998.

JONES, Kathleen. The Making of Social Policy in Britain: From the Poor to the New Labour. Londres: Continuum, 2005.

LAFER, Celso. A internacionalização dos direitos humanos: Constituição, Racismo e Relações Internacionais. Barueri: Manole, 2005.

LEAL, António da Silva. O direito à segurança social. p. 335-372. In: MIRANDA, Jorge (Coord.) Estudos sobre a Constituição. v. II, Lisboa: Petrony, 1978.

LIVELLARE, Carlos Alberto. La prevision social en la republica argentina. Arquivos do Instituto Brasileiro de Direito Social Cesarino Jr. São Paulo: p 23. 1997. 
MAGANO, Octávio Bueno. Reforma da previdência. Apresentado no XVII Congresso brasileiro de Direito Constitucional de 22 a 24 de maio de 1996. In: Caderno de Direito Constitucional e Ciência Política. São Paulo: v.5, n. 18, p. 184-186, jan./mar. 1997.

MAGNO, Pietro. Appunti su linee di riforma della previdenza. Il diritto del lavoro. Roma: v. 71 n $^{\circ} 4$ p. 275.1997.

MAROTTA RANGEL, Vicente. Direito e relações internacionais. 5ª Ed. RT, 1997. . Os sujeitos de Direito Internacional, em Direito Internacional Público. Escola da Guerra Naval. Rio de Janeiro, 1974.

MARTINEZ, Wladimir Novaes. Temas atuais de previdência social. São Paulo: LTr, 1998.

. Princípios de direito previdenciário. 3ª ed. São Paulo: LTr, 1995.

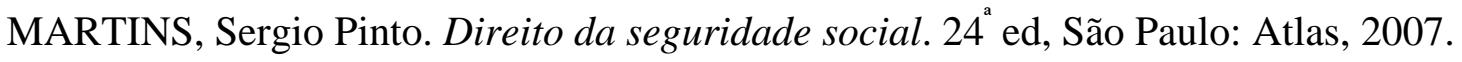
. Reforma da previdência social. São Paulo: LTr. Revista de Previdência Social, v 21 n²29, p. 1224/1231, dezembro de 1999.

. Direito Adquirido e Reforma Previdenciária. São Paulo: LTr. Revista de Previdência Social, São Paulo, v. 23, n. 222, p. 453-457, mai. 1999.

. Déficit da Previdência e a administração da seguridade pelo INSS. Jornal Valor Econômico, 17 de abril de 2003, p. E6.

Mercosul e a Seguridade Social. São Paulo: LTr. Revista de Previdência Social, São Paulo, n. 181, 1995.

Reforma previdenciária e déficit do sistema. São Paulo: LTr. Revista de Previdência Social, São Paulo, v. 28, n. 268, p. 146/151, mar. 2003.

MATTIA, Persiani. Commentario della riforma previdenziale. Padova: Giuffrè Editore, 1995. 
MAYDELL, Bernd von. Perspectivas da seguridade social. In: SEMINÁRIO INTERNACIONAL RELAÇÕES DE TRABALHO, Anais... Brasília: MTb, 1998.

MESA-LAGO, Carmelo. El desarrollo de la seguidad socal en America Latina. Santiago de Chile: Estudios e informes de la CEPAL, n.43,LC/G. 1334, 1985.

Las reformas de las pensioes en America Latina y la posición de los organismos internacionales. In: Revista de la CEPAL, n. 60, p. 73-94, Santiago de Chile, 1996.

MORAES, Marcelo Viana Estevão de. Globalização, integração regional e proteção social. A previdência social e o Mercosul. . São Paulo: LTr. Revista de Previdência Social, São Paulo, n. 178, set. 1995.

MORAIS, Antônio Glaucius de. Parecer CJ n. 1640-A/99. São Paulo: LTr. Revista de Previdência Social, v. 23, n. 222, p. 515-522, mai. 1999.

NETO, Caetano Lagrasta. Mercosul e integração legislativa: O papel da magistratura perante a justiça social. São Paulo. Revista dos Tribunais. nº. 742, 1997.

NETTO, Juliana Presotto Pereira. A previdência social em reforma. São Paulo: LTR, 2002.

OLIVEIRA, Francisco Eduardo Barreto de. Uma visão geral dos sistemas de previdência na Europa. São Paulo: In Seguridade, Ano 1 Número 1, p. 5-7, 2. ed., Publicada pelo Instituto Cultural de Seguridade Social.

ORSZAG, P. R.; STIGLITZ, et al. Rethinking pension reform: ten myths about social secutity systems. Washington, D.C: World Bank, mimeo, 1999.

ORTEGA, Leonor. A experiência chilena na previdência social. Disponível em: http://www.ufsc.br/latinidad/artigos/prevchil.html .

PASTOR, Almansa J. M. Derecho de La Seguridad Social. 7.ed. Madrid: Tecnos, 1991.

PENI, Roberto. O Sistema jurídico da previdência social. Buenos Aires: Revista de direito do Mercosul, v. 2 nº 1 p 13-16, 1998. 
PERES, Antonio Galvão. Contrato Internacional de Trabalho: novas perspectivas. São Paulo: LTr, 2004.

PIERDONÁ, Zélia Luiza. O Direito previdenciário como direito fundamental. Revista de Direito Social, ${ }^{\circ}$ 6, p. 38-51, 2002.

PINHEIRO, Vinícius Carvalho. Argentina y la seguridad social - el sistema de capitalización hizo inviable el equilibrio de las cuentas públicas. Disponível em http://www.redsegsoc.org.uy/Vinicius-Carvalho-Argentina-Esp.htm.

PIMENTA BUENO, José Antonio. Direito Público Brazileiro e a analyse da Constituição do Império. Rio de Janeiro: Typographia Imp. E Const. De J. Vileneuve E.C. , 1857.

PIOVESAN, Flávia (coordenação). Direitos humanos, globalização econômica e integração regional: desafios do direito constitucional internacional. S. Paulo: Max Limonad, 2002.

PLÁ RODRIGUEZ, Américo. A perspectiva da seguridade social. In: SEMINÁRIO INTERNACIONAL RELAÇÕES DE TRABALHO, Anais... Brasília: MTb, 1998.

POGGE, Thomas. La pobreza en el mundo y los derechos humanos. Tradução de Ernest Weikert García. Barcelona: Paidós, 2005.

PRADO, Antonio. A controvérsia da crise do fordismo e a transição pós-fordista: algumas reflexões sobre o caso brasileiro. In: EMPREGO e desenvolvimento tecnológico: processos de integração regional. São Paulo: DIEESE, 1999.

REALE, Miguel. A globalização da economia e o direito do trabalho. LTr: revista legislação do trabalho, São Paulo, v. 61, n. 1, p. 11-13, jan. 1997.

ROCHA, Daniel Machado da. O direito fundamental à Previdência Social na perspectiva dos princípios constitucionais diretivos do sistema previdenciário. Porto Alegre: Livraria do Advogado, 2004.

RIBEIRO, Júlio César Garcia. A previdência social do regime geral na constituição brasileira. São Paulo: LTr, 2001. 
ROMITA, Arion Sayão. Globalização da economia e direito do trabalho. São Paulo: LTr, 1997.

RUPRECHT, Alfredo J.. Direito da seguridade social. São Paulo: LTr, 1996.

RUSSOMANO, Mozart Victor. Curso de previdência social. Rio de Janeiro: Forense, 1988.

SAAD, Teresinha Lorena Pohlmann. Mercosul e a seguridade social integrada. São Paulo: LTr. Revista de Previdência Social, São Paulo, n. 179, p. 715, out. 1995.

SANTOS, Waldemar Alves dos et. al. Direito do trabalho na integração regional. São Paulo: Observador Legal Ed. 2002.

SERAU JUNIOR, Marco Aurélio. Seguridade Social como Direito Fundamental Material. Curitiba: Juruá, 2009.

SIMM, Zeno. Os direitos fundamentais e a Seguridade Social. São Paulo: LTr, 2005.

SIMÕES, Aguinaldo. Princípios de Segurança Social - Previdência e Assistência Social. São Paulo: 1967.

SILVA, Diana de Lima; PASSOS, Edésio (Coords.). Impactos da globalização: relações de trabalho e sindicalismo na América Latina e Europa. São Paulo: LTr, 2001.

SILVA, Walküre Lopes Ribeiro da. Crise de representatividade e participação dos sindicatos em políticas ativas de emprego. Tese (Titular de Direito do Trabalho) Faculdade de Direito da Universidade de São Paulo. São Paulo, 2001

SINGER, Paul. Globalização e desemprego: diagnóstico e alternativas. São Paulo: Contexto, 2001.

STELZER, Joana. União europeia e supranacionalidade: desafio ou realidade?. Curitiba: Juruá, 2000.

SUNDFELD, Carlos Ari; VIEIRA, Oscar Vilhena (Coord.). Direito global. São Paulo: Max Limonad, 1999. 
SÜSSEKIND, Arnaldo Lopes. A globalização da economia e o confronto entre os neoliberais e os adeptos do Estado Social. Jornal Trabalhista, Brasília, n. 742, p. 7-10, 11 jan. 1999.

TANASESCU, Elena Simina. Sur la Constitution européenne ou l'emergente d'um droit vonstitutionnel européen. In VRABIE, Genoveva (organização). L'évolution des concepts de la doctrine classique de droit constitutionne, Institutul European, Iasi, 2008.

VAN PARIJS, Philippe; VANDERBORHT, Yannick. La renta básica: una medida eficaz para luchar contra la pobreza. Tradução de David Casassas. Barcelona: Paidós, 2006.

VIEIRA, Oscar Vilhena. Realinhamento constitucional. In VIEIRA, Oscar Vilhena, SUNFELD, Carlos Ari. Direito Global. S. Paulo: Max Limonad, 1999.

VILLELLA, José Corrêa. Seguridade Social e a dignidade humana: algumas considerações. p. 357-455. In: FREITAS JUNIOR, Antonio Rodrigues de. Direito do Trabalho e Direitos Humanos. São Paulo: BH Editora e Distribuidora de Livros, 2006.

VRABIE, Genoveva. Le Constitucionnalisme Européen - Phénomène complexe et intégrateur. In VRABIE, Genoveva (organização). L'évolution des concepts de la doctrine classique de droit constitutionne, Institutul European, Iasi, 2008.

WACQUANT, Loïc. Punir os pobres: a nova gestão da miséria nos Estados Unidos [A onda punitiva]. 3. ed. rev. e ampl. Trad. De Sergio Lamarão. Rio de Janeiro, REVAN, 2007.

WILLBORN, Steven L.. Social security in united states of America . International Encyclopedia of Laws. Volume 4 - Social Security Law, p. 88-131, 1999.

WOJTYCZEK, Krzysztof. Les fonctions de la constitution écrite dans le contexte de la mondialisation. In VRABIE, Genoveva (organização). L'évolution des concepts de la doctrine classique de droit constitutionne, Institutul European, Iasi, 2008. 